Jurnal Iqtisad: Reconstruction of Justice and Welfare for Indonesia - Vol. 6, No 2 (2019) P-ISSN: 2303-3223; E-ISSN: 2621-640X

\title{
Kontekstualisasi Maqashid Shari'ah Dalam Sustainable Development Goals
}

\author{
Moh. Farid Fad \\ (Dosen Fakultas Ilmu Tarbiyah dan Keguruan UIN Walisongo Semarang) \\ Email: mohammadfarid@,walisongo.ac.id
}

\begin{abstract}
Abstrak
Proses pembangunan suatu bangsa tak akan pernah lepas dari keterkaitan dengan bangsa-bangsa lain di dunia. Namun di sisi lain, pembangunan seringkali hanya menekankan pada aspek pertumbuhan, justru melupakan unsur terpenting yaitu pemerataan. Akibatnya kurva kemiskinan bukannya menurun, melainkan tetap menjadi problem tersendiri hingga menciptakan gap yang menganga. Guna merespons problemproblem mendasar, dunia merespons dengan menetapkan tujuan pembangunan berkelanjutan (sustainable development goals) yang memuat 17 point. Lalu bagaimanakah konstekstualisasi tujuan hukum Islam kontemporer dalam merespons amanah SDGs ini? Jenis metode yang digunakan dalam penelitian ini adalah metode kualitatif. Setelah data terkumpul, dilakukan analisis dengan menggunakan metode deskriptif-analitis guna mendapatkan interpretasi kritis atas gambaran SDGs dalam perspektif maqashid syari'ah. Penelitian menunjukkan bahwa Sustainable Development Goals yang terangkum dalam 17 poin The Global Goals amatlah selaras dengan prinsipprinsip tujuan hukum Islam kontemporer, yaitu maqashid syari'ah versi Jasser Auda.
\end{abstract}

\begin{abstract}
The process of building a nation will never be separated from relations with other nations in the world. But on the other hand, development often only emphasizes the aspect of growth, it forgets the most important element, namely equity. As a result, the poverty curve is not decreasing, but it remains a problem in itself to create gaping gaps. In order to respond to fundamental problems, the world responds by setting sustainable development goals that contain 17 points. Then how is the contextualization of the objectives of contemporary Islamic law in response to the mandate of the SDGs? The type of method used in this study is a qualitative method. After the data is collected, an analysis is performed using descriptive-analytical methods to get a critical interpretation of the SDGs picture in the perspective of maqashid shari'ah. Research shows that the Sustainable Development Goals, which are summarized in 17 points of The Global Goals, are very much in harmony with the principles of the objectives of contemporary Islamic law, namely the Maqashid shari'ah version of Jasser Auda.
\end{abstract}

Keywords: sustainable development goals, maqashid shari'ah, contextualization.

\section{A. Pendahuluan}

Pada hakikatnya proses pembangunan suatu bangsa merupakan sebuah proses berkelanjutan antar berbagai dimensi, baik ekonomi, sosial maupun lingkungan yang berorientasi demi kemaslahatan umat. Namun tanpa disadari, dampak pembangunan bisa merugikan serta mengganggu keberlangsungan kehidupan umat manusia.

Sebenarnya, perhatian dunia pada dampak pembangunan ini telah lama disadari. Diawali dari agenda pelaksanaan KTT di Stockholm, Swedia tahun 
Jurnal Iqtisad: Reconstruction of Justice and Welfare for Indonesia - Vol. 6, No 2 (2019) P-ISSN:

1972. Pada pertemuan itu digapai persetujuan tentang relasi antara problem lingkungan yang dikorelasikan dengan pembangunan berkesinambungan.

Selain persoalan lingkungan hidup, seringkali pembangunan bangsa hanya memfokuskan pada pertumbuhan, dengan mengesampingkan pemerataan hasil pembangunan. Akibatnya adalah semakin terpuruknya sebagian warga dunia dalam kubangan kemiskinan hingga semakin melebarnya jurang perbedaan antara yang kaya dan miskin.

Nampaknya problem kemiskinan dan lingkungan akan menjadi permasalahan yang tidak akan pernah sirna. Dunia merespons dengan mengadakan konferensi pada September 2000 diikuti 189 negara dengan mendeklarasikan kesepakatan yang dikenal dengan The Millenium Development Goals (MDG's). Tujuannya antara lain meniminalisir jumlah kemiskinan hingga $50 \%$ di tahun $2015 .{ }^{1}$

Dengan berakhirnya era MDGs, kemudian saat ini dunia memasuki era SDGs (Sustainable Development Goals), yang diawali lewat pertemuan yang diselenggarakan pada 25-27 September 2015 di markas PBB, New York, Amerika Serikat. Agenda ini adalah rangkaian seremonial pengesahan SDGs yang diikuti delegasi dari 193 negara.

Konsepsi SDGs muncul pada konferensi yang diagendakan oleh PBB di Rio de Jainero tahun 2012. Capaian yang ingin dituju dalam agenda itu adalah mencapai tujuan kolektif yang bersifat universal yang mencakup tiga dimensi pembangunan berkelanjutan: social, ekonomi dan lingkungan. ${ }^{2}$

Namun, pada tataran riilnya, prinsip-prinsip itu tidak banyak ditemukan di komunitas masyarakat Muslim. ${ }^{3}$ Apalagi berdasarkan indeks HDI (Human Development Indeks) bahwa umat muslim menempati tingkat yang masih rendah apalagi unsur-unsur utama yang dipakai dalam HDI itu mencakup level

\footnotetext{
${ }^{1}$ Ishartono dan Santoso Tri Rahardjo, Sustainable Development Goals (SDGS) dan Pengentasan Kemiskinan, Share: Social Work Journal, Vol. 6., No. 2, 2016, Fisip Universitas Padjajaran, hlm. 159.

${ }^{2}$ Ibid, hlm. 163.

${ }^{3}$ Jasser Auda, Maqasid al-Shariah as Philosophy of Islamic Law: A Systems Approach, (London: the International Institut of Islamic Thougth, 2007), xxii-xxiii.
} 
Jurnal Iqtisad: Reconstruction of Justice and Welfare for Indonesia - Vol. 6, No 2 (2019) P-ISSN:

pendidikan, buta aksara, emansipasi wanita dan ekonomi, umat Islam masih di bawah level minimal. ${ }^{4}$

Hal ini yang memunculkan kegundahan tersendiri bagi Jasser Auda, dan menimbulkan pertanyaan, apa yang sebenarnya dituju oleh hukum Islam? Dimanakah hikmah dan kesejahteraan umat sebagai dasar tujuan hukum Islam? Artikel ini akan berusaha menguraikan konsep SDGs dalam perspektif maqashid syari'ah Jasser Auda.

\section{B. Metode}

Jenis metode yang dipakai dalam penelitian ini adalah metode kualitatif. Hal ini disebabkan oleh apa yang dilakukan dalam penelitian ini yang tidak bertujuan untuk mengukur hubungan antar variabel. Tetapi bertujuan untuk menganalisis Sustainable Development Goals (SDGs) dalam perspektif maqashid syari'ah Jasser Auda. Setelah data terkumpul, akan dilakukan analisis dengan menggunakan metode deskriptif-analitis, yaitu menggambarkan secara sistematis fakta yang ditemukan secara akurat dan cermat, serta dilakukan analisis secara kualitatif guna mendapatkan pemahaman terhadap problem yang diteliti secara lebih mendalam.

\section{Hasil Penelitian dan Pembahasan}

\section{Biografi Singkat Jasser Auda}

Jasser Auda merupakan cendekiawan muslim yang lahir di Kairo, Mesir. Pendidikannya dimulai di Kairo. Ia sarjana teknik di Universitas Kairo pada tahun 1998. Selain itu pada tahun 2001 beliau mendapat gelar B.A. (sarjana muda) diperoleh dari program studi Islamic Studies pada Islamic American University di Amerika Serikat. Kemudian pada tahun 2004, ia menyelesaikan Master Fiqh dari Universitas Islam Amerika di Michigan dengan fokus kajian Maqasid al-Syari'ah atau Tujuan Hukum Islam. Selanjutnya pada tahun 2006 ia memperoleh gelar Ph.D di Waterloo University, Kanada, dengan fokus analisis sistem. Gelar Ph.D

\footnotetext{
${ }^{4}$ Ibid, hlm. xxii
} 
Jurnal Iqtisad: Reconstruction of Justice and Welfare for Indonesia - Vol. 6, No 2 (2019) P-ISSN:

kedua diraih di University of Wales, Inggris, dengan konsentrasi Filsafat Hukum Islam, tahun $2008^{5}$. Ketika di Kairo, ia juga melakukan talaqqi klasik di masjid Jami' al-Azhar yakni berupa menghafal Qur'an, mengkaji hadits al- Bukhari dan Muslim, fikih, Isnad dan Takhrij serta Usul Fikih. ${ }^{6}$

Ia merupakan pendiri dan direktur Maqashid Research Center di London, Inggris. ${ }^{7}$ Selain itu, karier Jasser Auda adalah meliputi Presiden Institut Maqasid Global, anggota Dewan Fiqih Amerika Utara, Dewan Fatwa Eropa dan rekan di Akademi Fiqih India, profesor di universitasuniversitas di Alexandria di Mesir Waterloo, Carleton dan Ryerson di Kanada, Perdamaian Internasional di Afrika Selatan, Universitas Islam di Sanjaq, Qatar Faculty of Islamic Studies, Universitas Amerika Sharjah di UAE dan Universitas Bahrain. Ia mengajar Hukum Islam di berbagai negara, termasuk di Indonesia. ${ }^{8}$

Adapun karya-karyanya kurang lebih 25 buku yang ditulis dalam Bahasa Inggris dan Bahasa Arab, beberapa diantaranya diterjemahkan ke 25 bahasa. ${ }^{9}$ Adapun buku terakhirnya adalah Maqasid al-Shariah as Philosophy of Islamic Law: a Systems Approach. Kedua karya ini, diterbitkan oleh Institut Pemikiran Islam Internasional (IIIT) di London pada tahun $2007 .^{10}$

\section{Maqashid Klasik}

Maqashid al-syari'ah secara etimologi terbagi atas dua kata, yakni maqasid dan syari'ah. Kata maqashid, bentuk plural dari maqsid, dapat

${ }^{5}$ Jasser Audah, Al-Maqashid untuk Pemula, Terj. Ali Abdelmo'im, (Yogyakarta: SUKAPress, 2013), hlm. x

${ }^{6}$ Ibid., hlm. 137-140.

${ }^{7}$ Ibid.,

8 Jasser Auda, biografi, (online), Tersedia : http://www.jasserauda.net/ portal/biography/?lang=en), diakses 12 Juli 2019

${ }^{9}$ Ibid.,

${ }^{10}$ Siti Mutholingah, dkk., Relevansi Pemikiran Maqashid Al-Syari'ah Jasser Auda Terhadap Sistem Pendidikan Islam Multidisipliner, Jurnal Ta'limuna, Vol. 7 No. 2, September 2018, Hlm. 94. 
Jurnal Iqtisad: Reconstruction of Justice and Welfare for Indonesia - Vol. 6, No 2 (2019) P-ISSN:

diartikan sebagai beberapa tujuan, sedangkan asy-syari'ah yakni sarana menuju sumber air sebagai sumber kehidupan. ${ }^{11}$

Kajian maqashid telah menjadi diskursus penting dalam filsafat hukum Islam. Maqashid merupakan konsep metodologi yang berperan penting dalam proses beristinbath hukum serta menjadi pijakan penting dalam pengembangan metodologi hukum Islam. Begitu pentingnya hingga para ahli hukum Islam menetapkannya sebagai salah satu kriteria seseorang dikatakan mujtahid. Mengutip pendapat Syatibi, ar-Raisuni berpendapat:

Untuk pertamanya, dalam tahap tertentu, yang dapat diketahui, kami menemukan bahwa prasyarat utama guna mencapai tingkatan ijtihad adalah memahami maqashid syari'ah secara baik. Kami juga menetapkan syarat kedua dan ini yang terakhir, juga tak boleh keluar dari pemahaman terhadap maqashid, yaitu diperbolehkannya beristinbath hukum berdasarkan interpretasi terhadap maqashid ${ }^{12}$.

Ibn Asyur mengatakan, sebagaimana dikuti al-Ulwani ${ }^{13}$, bahwa mengabaikan maqashid merupakan sebab terjadinya kemandegan dalam mengembangkan hukum Islam dan menghilangnya pengungkapan hukum-hukum yang bermanfaat, serta membuat orang cenderung jemu pada persoalan hillah yang menjadi kecenderungan berpikir para yuris.

Dari berbagai penjelasan di atas, setidaknya maqasid al-syari'ah dapat dipahami sebagai maksud dari rangkaian hukum Islam pada terbentuknya kemaslahatan dan keadilan masyarakat. Dengan kata lain, hukum diciptakan Allah dalam rangka merealisasi kemashlahatan hambaNya, bukan untuk hukum itu sendiri. Tak satupun dari hukum Allah itu tidak memiliki tujuan, semuanya bertujuan, hingga bila hukum itu tidak

\footnotetext{
${ }^{11}$ Ibn Mansur al-Afriqi, Lisan al- 'Arab (Beirut: Dar ash-Shadr, t.th), VIII. p. 175.

12 Ahmad ar-Raisuni, Nazariyat al-Maqashid 'Inda al-Imam asy-Syatibi, Herndon: International Institute of Islamic Thought, 2007, hlm. 343.

${ }^{13}$ Taha Jabir al-Ulwani, Muqaddimat al-Ma'had dalam Ahmad ar-Raisuni, Nazariyat alMaqashid 'Inda al-Imam asy-Syatibi, Herndon: International Institute of Islamic Thought, 2007, hlm. 13.
} 
Jurnal Iqtisad: Reconstruction of Justice and Welfare for Indonesia - Vol. 6, No 2 (2019) P-ISSN:

memiliki tujuan, maka sama dengan membentuk hukum yang bersifat siasia ('abats), dan hal yang demikian tentu mustahil terdapat pada hukumhukum Allah.

Maqashid al-shari'ah ditujukan demi mengupayakan kemaslahatan di dunia dan akhirat secara simultan. Prinsip kemaslahatan itu terealisir dengan terpenuhinya tiga kebutuhan pokok; primer, sekunder, dan tersier (dharuriyah, hajiyah dan tahsiniyah). Kebutuhan primer (dharuriyah) tercapai jika ada peneguhan terhadap kelanggengan lima hal pokok (mabadi' al-khams, dharuriyat al-khams); jiwa, agama, akal, harta, dan keturunan.

Tingkatan kedua, kebutuhan hajiyat (sekunder), dimana jika tidak terwujud tidak sampai merugikan keselamatannya, melainkan justru mengalami kesulitan. Syariat Islam meminimalisir kesulitan itu. Adanya hukum rukhshah, adalah sebagai misal dari kepedulian syari’at Islam akan hal ini.

Tingkatan ketiga, tahsiniyat ialah level kebutuhan yang bila tidak tercapai tidak sampai beresiko mengancam wujud salah satu dari lima unsur asasi di atas dan tidak juga mendatangkan masyaqqat. Tingkatan ini bersifat pelengkap, hal-hal yang merupakan kelayakan menurut tradisi yang selaras dengan akhlak dan moral. Jenis ini lebih menekankan perhatian pada etika dan estetika, masuk pada kategori ini misalnya prinsip terkait kebersihan dan bantuan kemanusiaan. 
Jurnal Iqtisad: Reconstruction of Justice and Welfare for Indonesia - Vol. 6, No 2 (2019) P-ISSN:

Klasifikasi maqashid syari'ah klasik

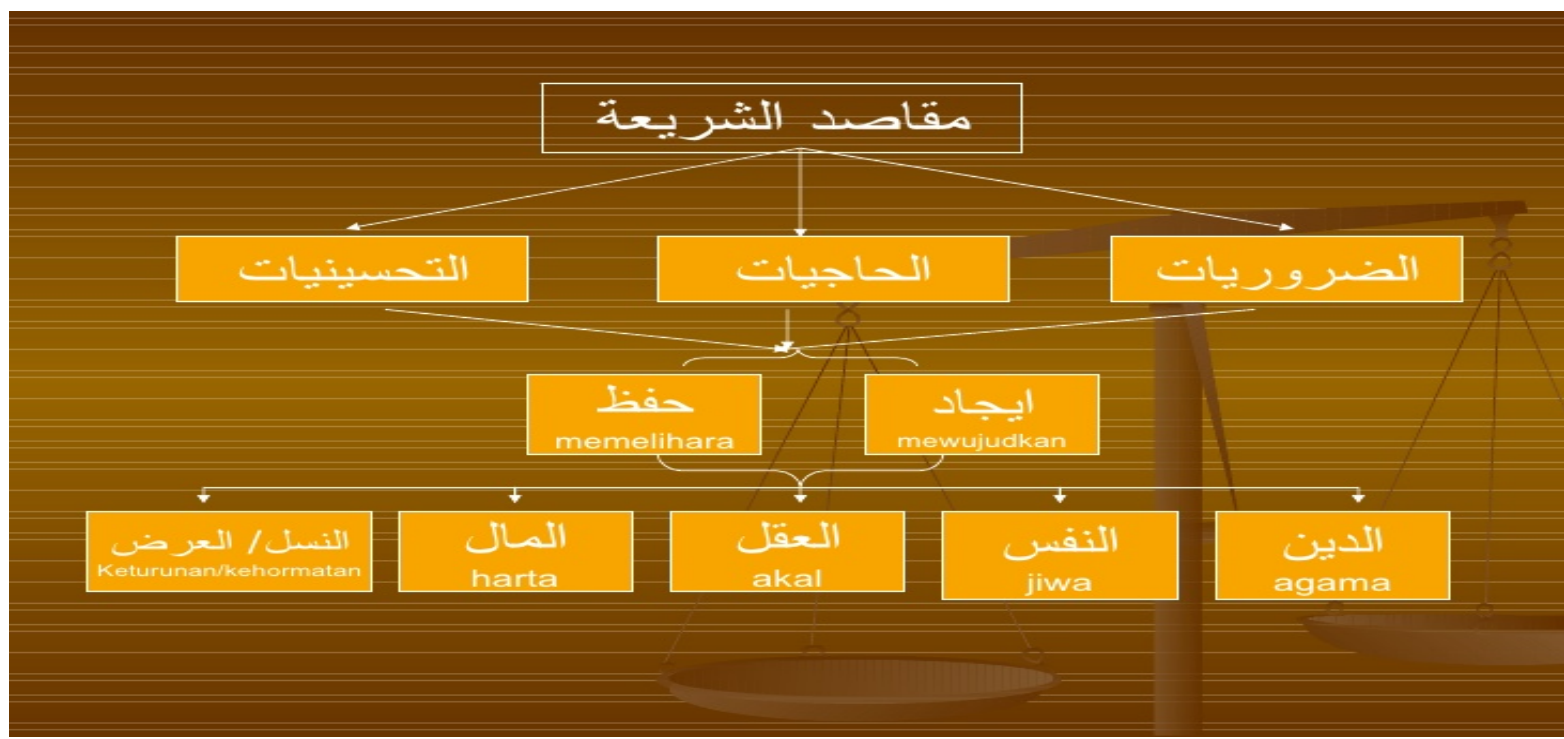

\section{Latar Belakang Pemikiran Jasser Auda}

Pemikiran Jasser Auda dalam mengkontekstualisasi ulang maqashid al-syariah sebagai filsafat hukum Islam dilatarbelakangi oleh anggapannya terhadap maqashid al-syari'ah klasik sudah tidak relevan dengan kondisi umat manusia saat ini sebab zaman makin berkembang, sehingga perlu adanya reorientasi sekaligus revisi terhadap maqashid alsyariah tersebut. $^{14}$

Hal ini dimaksudkan agar nantinya produk hukum Islam (syari'at) yang berlandaskan maqashid al-syariah ini akan selalu relevan sampai kapanpun dan dimanapun. Jasser Auda mengkritik klasifikasi keniscayaan hlm. xxvi

${ }^{14}$ Jasser Auda, Maqasid al-Shariah as Philosophy of Islamic Law: A Systems Approach, 
Jurnal Iqtisad: Reconstruction of Justice and Welfare for Indonesia - Vol. 6, No 2 (2019) P-ISSN:

(dharurat) model maqashid klasik sebagaimana yang telah dijelaskan dengan beberapa alasan ${ }^{15}$ :

a. Lingkup maqashid klasik ialah keseluruhan hukum Islam, namun gagal memasukkan tujuan khusus untuk keputusan tunggal atau kelompok skrip yang mencakup topik atau bab fiqh tertentu;

b. Maqashid klasik cenderung bersifat individu dan kurang bersifat masyarakat, kemanusian dan umum

c. Maqashid klasik tidak menjamin kebanyakan nilai-nilai dasar dan universal seperti prinsip kebebasan dan keadilan;

d. Maqashid terdahulu disimpulkan dari mempelajari literatur fiqh dan bukan sumber aslinya.

Selain itu, menurutnya, maqashid syari'ah klasik lebih berciri individual, yaitu protection dan preservation itu harus direorientasikan menjadi maqashid yang lebih bernilai universal, kemasyarakatan dan kemanusiaan. ${ }^{16}$ Reorientasi inilah yang menjadi distingsi antara pemikiran Auda dengan pemikiran ulama-ulama ushul fiqih terdahulu.

\section{Dasar Pendekatan Sistem}

Auda membidik maqashid syariah dengan metoda sistem, sistem yang ia artikan sebagai a set of interacting units or elements that forms an integrated-whole intended to perform some function ${ }^{17}$. Artinya, sistemik selalu terkait dengan elemen, unit dan sub sistem yang membentuk satu kesatuan hierarkis yang bekerjasama secara berkesinambungan, mempunyai proses guna mencapai tujuan tertentu.

Auda secara spesifik mengartikan maqashid melalui empat arti; pertama, hikmah dibalik suatu hukum; kedua, tujuan ilahiyah dan basis moral yang menjadi tujuan hukum; ketiga, tujuan akhir yang ingin dicapai oleh hukum; dan keempat, mashalih.

\footnotetext{
${ }^{15}$ Ibid., hlm. 4

${ }^{16}$ Ibid, hlm. 248.

${ }^{17}$ Ibid., hlm. 33
} 
Jurnal Iqtisad: Reconstruction of Justice and Welfare for Indonesia - Vol. 6, No 2 (2019) P-ISSN:

Ia menekankan urgnesinya penggunaan maqashid al-syari'ah sebagai manat hukum seperti 'illat. Dia mengusulkan alternatif kaidah baru sebagai pengganti kaidah lama, yaitu ${ }^{18}$ :

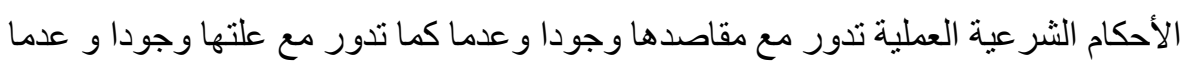

Hukum-hukum amaliyah selaras dengan maqashidnya sebagaimana ia bersama dengan ada atau tidak adanya illatnya. Auda mendasarkan konsep maqashidnya pada hadist sebagai berikut:

$$
\text { ي أَحَدُ الْعَصْرَ إِلَّا فِي بَنِي قُرَيْظَةَ }
$$

Artinya: Jangan ada satupun yang shalat 'Ashar melainkan di Bani Quraizhah (HR. Bukhari No. 4119).

Ia berargumen bahwa hadist di atas sebagai bukti yang jelas kebolehannya istinbath hukum berdasarkan dzan ghalib, karena beberapa sahabat yang berijtihad memahami bahwa tujuan dari sabda Nabi tersebut ialah untuk segera sampai ke Bani Quraidhah, dan tidak melulu perintah shalat Asar di Bani Quraidhah. Hingga sahabat yang menunaikan shalat Asar di jalan seolah bertentangan secara dzahir dengan perintah Nabi, sedangkan sebagian sahabat yang melakukan shalat di tempat tujuan berpedoman pada teks dzahirnya saja. Diamnya (taqrir) Nabi adalah bukti bahwa Beliau menjustifikasi kedua metode pemahaman tersebut. ${ }^{19}$

Auda berargumen pada beberapa ijtihad Umar yang kontradiksi dengan dzahirnya nash dengan berpedoman pada maslahat atau maqashid seperti keputusan Umar dengan tidak menetapkan hukum potong tangan bagi pencuri di masa paceklik, tidak memberi nisbah zakat pada muallaf yang mampu. ${ }^{20}$

18 Jasser Auda, Maqāṣid al-Ahkam al-Shar'iyyah wa 'Ilaluha, diunduh dari http://www.jasserauda.net/modules/Research_Articles/pdf/article1A.pdf diakses pada 13 Juli $2019 \mathrm{hlm} .9$

${ }^{19}$ Jasser Auda, Op.Cit, hlm. 9.

${ }^{20}$ Ibid., hlm. 9-10. 
Jurnal Iqtisad: Reconstruction of Justice and Welfare for Indonesia - Vol. 6, No 2 (2019) P-ISSN:

\section{Pendekatan Sistem}

Pendekatan sistem yang digunakan oleh Auda ini meliputi 6 fitur yang saling berkaitan sebagai berikut:

\section{a. Sifat Kognitif}

Fitur kognitif (idrakiyah, cognition) menawarkan sistem hukum Islam yang memilah wahyu dan kognisinya. Artinya, fikih digeser dari klaim sebagai ranah pengetahuan Ilahiyah menuju ranah kognisi manusia akan pengetahuan Ilahiyah. Diferensiasi yang tegas antara syariah dan fikih ini berdampak pada tidak terdeteksinya opini fikih praktis yang diklaim sebagai pengetahuan Ilahiyah. $^{21}$

Guna membongkar validasi seluruh pengetahuan tentang teks, Auda menekankan urgensinya mendistingsi teks dari interpretasi orang terhadap teks ${ }^{22}$. Hukum Islam merupakan hasil dari ijtihad para yuris yang mencoba mengungkap makna tersembunyi atau implikasi praktis dari syari'at. Hingga sifat kognitif dari hukum Islam ini diperlukan dalam memvalidasi pandangan yang variatif dalam penetapan hukum Islam. ${ }^{23}$

b. Keholistikan

Fitur kulliyyat (wholeness) ini mengurai kelemahan ushul fikih klasik yang cenderung menerapkan pendekatan atomistik dan reduksionis. Paradigma atomistik terdeteksi dari sikap mengandalkan satu nash guna mengurai kasus-kasus yang

${ }^{21}$ Jasser Auda, Membumikan Hukum Islam Melalui Maqashid Shari'ah, Bandung: PT Mizan Pustaka, 2015, hlm. 12. hlm. 45

${ }^{22}$ Jasser Auda, Maqasid al-Syariah as Philosophy of Islamic Law: Syistems Approch,

${ }^{23}$ Ibid., hlm. 46 
Jurnal Iqtisad: Reconstruction of Justice and Welfare for Indonesia - Vol. 6, No 2 (2019) P-ISSN:

dihadapinya, tanpa melihat nash-nash yang lain. Solusi yang ditawarkan Auda ialah menjadikan seluruh ayat Al-Qur'an sebagai konsideran dalam menetapkan hukum Islam ${ }^{24}$.

Implikasi dari paradigma macam ini adalah cara pandang atomis selalu melihat sesuatu pada relasi sebab-akibat. Sementara itu, metode sistemik memandang bahwa sebab dan akibat berkorelasi sebagai satu unit dari keseluruhan.

c. Keterbukaan

Menurut Auda, tidak ada istilah penutupan pintu ijtihad dalam hukum Islam sebagaimana dikemukakan oleh para ulama klasik. Hal ini dikarenakan hukum Islam dapat dikembangkan sesuai dengan kebutuhan zaman jika memang menghadapi perubahan-perubahan baru dalam beberapa aspek kehidupan manusia. $^{25}$

Sistem yang terbuka diartikan sebagai sistem yang terkoneksi dengan situasi lingkungannya. Dengan demikian, metodologi hukum Islam pada dasarnya mengembangkan sistem tertentu terkait peristiwa-peristiwa baru. Misalnya maslahah, qiyas dan i'tibar al- 'urf.

Fitur keterbukaan (infitahiyah, openness) ini berfungsi memperluas jangkauan urf. Bila sebelumnya urf mengakomodir adat kebiasaan yang beda dengan tradisi Arab, maka urf dalam konteks ini titik optimumnya pada pandangan dan wawasan keilmuan sang yuris. Jadi, seorang ahli hukum harus memiliki wawasan yang luas sangat berperan dalam menghadapi isu-isu kontemporer. Setidaknya pendekatan ini meminimalisir

\footnotetext{
${ }^{24}$ Jasser Auda, Membumikan Hukum Islam, hlm. 12-13.

${ }^{25}$ Ibid., hlm. 47-48
} 
Jurnal Iqtisad: Reconstruction of Justice and Welfare for Indonesia - Vol. 6, No 2 (2019) P-ISSN:

kecenderungan literalisme umat Islam sekaligus membuka sistem hukum Islam pada kemajuan ilmu-ilmu sciences.

\section{d. Keterkaitan}

Setidaknya fitur ini memperbaiki sistem maqashid klasik. Pertama, jika maqashid klasik bersifat partikular hingga membatasi jangkauannya, maka fitur ini mengklasifikasi maqashid secara piramidal: maqashid umum ('ammah) yang ditelaah dari universalitas bagian hukum Islam, maqashid khusus (khassah) yang diteliti dari seluruh isi bab hukum Islam dan maqashid partikular (juziyyat) yang diturunkan dari suatu nash atau hukum tertentu. Kedua, perbaikan jangkauan yang lebih berdimensi sosial dan khalayak.

Meskipun dalam maqashid al-syariah sebagaimana dirumuskan oleh para ulama klasik terdapat hierarki dari maqashid yang paling mendasar yakni dzaruriyat, hajiyat, dan tahsiniyat, namun pada akhirnya antara ketiganya saling berhubungan dan berkaitan satu sama lain. Bahkan pemenuhan salah satu kebutuhan itu harus dalam rangka mewujudkan kebutuhan dasar di bawahnya. $^{26}$

\section{e. Multidimensionalitas}

Dalam hal ini Auda mengkritik para ulama ushul fiqih klasik yang cenderung berpikirnya hanya monolitik saja. Misalnya dalam ta'arud al-dalalah yang terkadang ada yang menganggap ada pertentangan ayat dalam al-Qur'an. ${ }^{27}$ Sebab, yang konstradiksi adalah dari sisi bahasa saja, bukan pada sisi logika yang selalu dikorelasikan dengan waktu saat teks dirumuskan. Bila logika ini

\footnotetext{
${ }^{26}$ Ibid., hlm 48

${ }^{27}$ Ibid., hlm. 50-51
} 
Jurnal Iqtisad: Reconstruction of Justice and Welfare for Indonesia - Vol. 6, No 2 (2019) P-ISSN:

dipakai, yang menjadi rujukan adalah: apakah secara substansi terdapat kontradiksi atau tidak atas teks-teks tersebut.

Pendekatan multidisipliner yang digagas oleh Jasser Auda dalam mengkaji maqashid al-syari'ah yaitu bahwa dalam mengembangkan maqashid al-syari'ah sebagai suatu disiplin hukum Islam amat membutuhkan disiplin-disiplin ilmu lain. Karena jika tidak dilakukan, teori hukum Islam akan selalu berada dalam skema literatur tradisional sehingga keputusan yang bersumber pada hukum Islam akan selalu ketinggalan zaman. ${ }^{28}$

Fitur taadudul al-ab'ad ini dapat menawarkan solusi atas dilema pertentangan antar dalil. Jadi kedua dalil yang tampak kontradiktif dapat dilerai dalam suatu konteks baru, yaitu dilalah al-maqashid. Caranya, nash yang lebih mengundang maslahah sesuai dengan tempat dan waktunya yang lebih dipilih. ${ }^{29}$

\section{f. Tujuan}

Dalam suatu sistem, tujuanlah yang menjadi sesuatu paling inti. Dalam hal ini maqashid hukum Islam itu merupakan inti dari hukum Islam itu sendiri. Kebertujuan hukum Islam ini meliputi kelima fitur sistem hukum Islam di atas yakni keutuhan, keterbukaan, sifat kognitif, inter-relasi, maupun multidimensionalitas. ${ }^{30}$

Fitur al-maqashidiyyah/purposefulness ini ditujukan pada narasi-narasi primer yaitu Al-Qur'an dan Hadist dan juga sumbersumber aqliyah yaitu istihsan, qiyas dan lainnya. Contoh fitur ini

${ }^{28}$ Ibid., hlm. 249

${ }^{29}$ Jasser Auda, Memahami Maqashid Syari'ah: Peranan Maqashid dalam Pembaharuan Islam Kontemporari, Selangor: PTS Islamika SDN, BHD, 2014, hlm. 51-59.

${ }^{30}$ Ibid., hlm. 54 
Jurnal Iqtisad: Reconstruction of Justice and Welfare for Indonesia - Vol. 6, No 2 (2019) P-ISSN:

adalah al-Qur'an dicermati dengan pendekatan holistik hingga ayat yang membahas keimanan, surat-surat, kisah-kisah Nabi, alam semesta dan kehidupan akhirat akan jadi gambaran utuh sehingga berperan dalam pembentukan hukum yuridis.

Teori sistem Jasser Auda dapat digambarkan sebagai berikut:

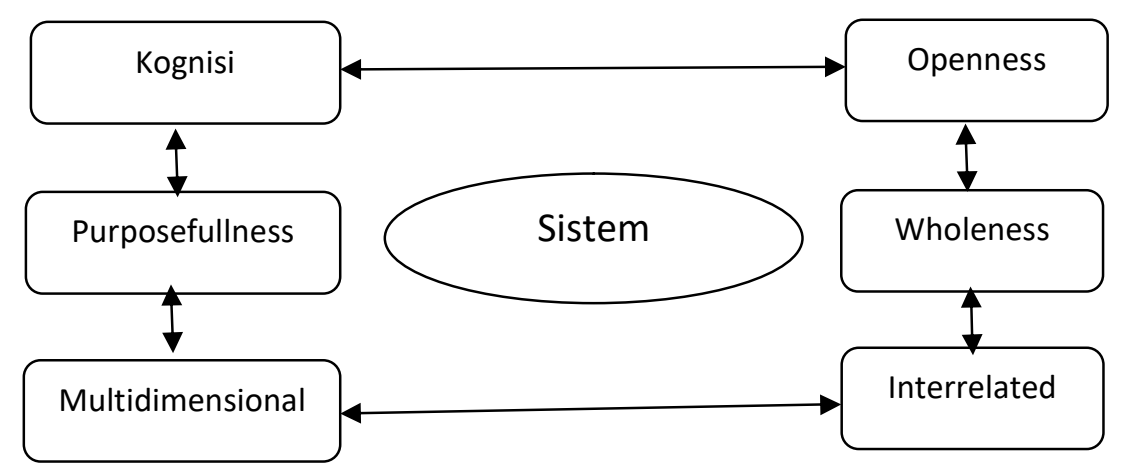

Jadi antara keenam fitur pendekatan sistem tersebut saling berkaitan satu sama lain, saling menembus dan berhubungan, sehingga membentuk keutuhan berpikir, dengan kebertujuan sebagai intinya. Mempertimbangkan efisiensi sebuah sistem diukur dari level ketercapaian tujuannya, maka efisiensi hukum Islam dinilai berdasarkan tingkat ketercapaian maqashid syari'ahnya. Dalam arti, sejauh mana efektivitas problem solvingnya terhadap permasalahan tertentu, apakah lebih berdaya guna dan lebih bermanfaat bagi umat dan kemanusiaan. ${ }^{31}$

Jasser Auda membuat klasifikasi/hierarki maqashid alsyari'ah kontemporer menjadi 3 tingkatan yaitu:

1) General maqashid (maqashid 'ammah) yaitu maqashid yang ditujukan pada keseluruhan hukum Islam termasuk di dalamnya dzaruriyat dan hajiyyat dengan ditambah tujuan maqashid yang baru yaitu keadilan. Oleh sebab itu, maslahat

${ }^{31}$ Amin Abdullah, Pengantar dalam Membumikan Hukum Islam Melalui Maqashid Shari'ah, Bandung: PT Mizan Pustaka, 2015, hlm. 11-12. 
Jurnal Iqtisad: Reconstruction of Justice and Welfare for Indonesia - Vol. 6, No 2 (2019) P-ISSN:

yang primer yang mencakup kewajiban menjaga jiwa, agama, akal, nasab, harta dan kehormatan itu masuk dalam bagian maqashid umum ini. Maqashid 'ammah adalah prinsip general yang ada pada semua atau sebagai besar kondisi tasyri', seperti kebebasan, keadilan dan kemudahan.

2) Partial maqashid (maqashid juz'iyyat) yaitu maqasid yang paling substantif dalam peristiwa hukum. Maslahah ini juga disebut rahasia atau hikmah (asrar). Permisalan maqashid ini adalah maksud dari rukhsah tidak puasa bagi yang tidak mampu ialah meminimalisir masyaqqat. Kebutuhan akan unsur kejujuran dan kuatnya ingatan dalam kesaksian. Dalam kriminal modern bisa jadi cukup dengan satu saksi adil dan tidak wajib ada dua saksi asal yang bersangkutan mampu memperlihatkan data yang valid dan sikap jujur. ${ }^{32}$

3) Specific maqashid (maqashid khassah) yaitu maqasid yang terhubung pada maslahah dalam problem tertentu, misalnya tidak boleh melukai perempuan dalam lingkup keluarga, dan tidak boleh menipu dalam perniagaan lewat apapun, dalam bab jinayat yang bertujuan membuat efek jera. ${ }^{33}$

4) Para yuris klasik menyusun maqashid al-syari'ah dalam tingkatan piramida, yang dimulai dari maqashid 'ammah sebagai centernya kemudian bercabang menjadi maqashid khassah dan terakhir maqashid parsial. Kemudian pada sisi lain diawali dari al-dharuriyah, hajiyah kemudian tahsiniyah.

\footnotetext{
${ }^{32}$ Retna Gumanti, Maqashid Syari'ah Menurut Jasser Auda (Pendekatan Sistem dalam Hukum Islam), Jurnal al-Himayah, Vol. 2 No. 1 Maret 2018, hlm. 113.

${ }^{33}$ Ibid., hlm. 5
} 
Jurnal Iqtisad: Reconstruction of Justice and Welfare for Indonesia - Vol. 6, No 2 (2019) P-ISSN:

Para ulama kontemporer menyusun skema prioritas bila terjadi kontradiksi antara maqasid satu dengan berpendapat bahwa maqashid syari'ah dengan segala levelnya bukan merupakan struktur yang bersifat piramid, dimana maqasid terbagi antara yang atas dan yang bawah, namun ia bagai lingkaran-lingkaran yang bersinggungan dan bertemu, yang saling terkait satu dan lainnya ${ }^{34}$.

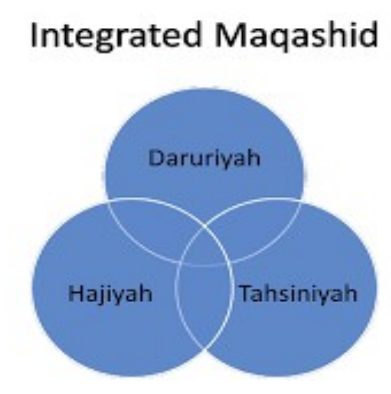

Untuk mengimplementasikan analisis system, maka berbagai upaya yang dapat direalisir ialah: 1) memvalidasi seluruh pengetahuan, 2) menghindari metode reduksionis dan atomistik menuju pendekatan holistik, 3) selalu terbuka dan memperbaharui pengetahuan, 4) senantiasa memandang sesuatu dari perspektif multi-dimensionalitas bukan kategorisasi biner, 5) melihat purposefulness sebagai inti berpikir $^{35}$.

Reorientasi maqashid al-syari'ah klasik menuju maqashid al-syari'ah kontemporer menurut Jasser Auda yaitu adanya perubahan dari maqashid al-syari'ah klasik yang bersifat protection (perlindungan) dan preservation menuju maqashid al-syari'ah yang bersifat development

\footnotetext{
${ }^{34}$ Jasser Auda, Maqasid al-Ahkam al-Shar'iyyah wa 'Ilaluha,

${ }^{35}$ Ibid.,
} 
Jurnal Iqtisad: Reconstruction of Justice and Welfare for Indonesia - Vol. 6, No 2 (2019) P-ISSN:

(pengembangan) dan right (kebebasan) ${ }^{36}$, bahkan Jasser Auda menyarankan guna pendayagunaan Sumber Daya Manusia (SDM) menjadi salah satu isu utama bagi kemaslahatan umat. $^{37}$

\section{SDGs}

Suistainable Development Goals (SDGs) adalah kesepakatan yang menjadi rujukan dalam skema pembangunan dan perundingan negaranegara di dunia. SDGs dikonsepsikan sebagai rumusan kerja untuk 15 tahun ke depan hingga tahun 2030.

Berbeda dengan MDGs yang lebih teknokratis, penyusunan butirbutir SDGs lebih inklusif yang melibatkan berbagai pihak termasuk Civil Society Organization (CSO). SDGs ini merupakan kesinambungan dari MDGs (Millennium Development Goals) yang telah berakhir pada 2015.

Pembuatan narasi SDGs sendiri memiliki berbagai kendala karena masih terdapat beberapa butir-butir target MDGs yang belum tercapai dan harus dikerjakan di dalam SDGs. Seluruh target, tujuan dan indikator dalam SDGs juga perlu menimbang perubahan kondisi global saat ini. ${ }^{38}$

Adapun tiga unsur yang menjadi indikator dalam konsep pengembangan SDGs yaitu, pertama terkait pembangunan manusia (human development), meliputi kesehatan dan pendidikan. Indikator kedua yang berwujud pada lingkungan kecilnya (social economic development), seperti sarana dan prasarana yang memadai, serta pertumbuhan ekonomi. Sementara itu, indikator ketiga terangkai pada

${ }^{36}$ Ibid., hlm. 21-23

${ }^{37}$ Ibid., hlm. 248

${ }^{38}$ Wahyuningsih, Millenium Development Goals (MDGS) dan Sustainable Development Goals (SDGS) dalam Kesejahteraan Sosial, Bisma; Jurnal Bisnis dan Manajemen, Vol. 11, No. 3, September 2017, hlm. 392. 
Jurnal Iqtisad: Reconstruction of Justice and Welfare for Indonesia - Vol. 6, No 2 (2019) P-ISSN:

lingkup yang lebih makro (environmental development), berupa ketersediaan kualitas lingkungan yang baik dan sumber daya alam. ${ }^{39}$

Sustainable Development Goals (SDGs) bias dikatakan sebagai konsorsium 193 pemimpin dunia pada 25 September 2015, tentang 17 Sasaran Global (The Global Goals) yang diharapkan dapat tercapai pada tahun 2030, yaitu $^{40}$ :

a. Nir-kemiskinan (no poverty): hilangnya kemiskinan dengan segala bentuknya di penjuru dunia;

b. Nir-kelaparan (zero hunger): hilangnya kelaparan, tercapainya ketahanan pangan, perbaikan gizi dan memicu budidaya pertanian yang berkesinambungan;

c. Kesejahteraan dan kesehatan yang baik (well-being and good health): tercapainya kehidupan yang sehat dan memicu kesejahteraan hidup demi seluruh masyarakat;

d. Pendidikan berkualitas (quality education): meningkatkan kesempatan belajar untuk seluruh orang dan menjamin pemerataan pendidikan yang berkualitas;

e. Kesetaraan gender (gender equality): menggapai kesetaraan gender dan memberdayakan kaum perempuan dan ibu;

f. Air bersih dan sanitasi (clean water and sanitation): menjamin keberlangsungan air bersih dan sanitasi yang sehat;

g. Energi terjangkau dan bersih (clean energy and affordable): menjamin akses terhadap sumber energi yang terpercaya, terjangkau, berkesinambungan dan modern untuk semuanya;

h. Pertumbuhan ekonomi dan pekerjaan yang layak (economic growth and decent work) menopang perkembangan ekonomi yang berkelanjutan,

\footnotetext{
${ }^{39}$ Ibid., hlm. 393.

${ }^{40}$ www.globalgoals.org dan satu-indonesia.com, diakses pada 14 Juli 2019
} 
Jurnal Iqtisad: Reconstruction of Justice and Welfare for Indonesia - Vol. 6, No 2 (2019) P-ISSN:

i. Inovasi, industri dan infrastruktur (innovation, industry and infrastructure): membangun infrastruktur yang memadai memicu peningkatan industri yang berkelanjutan;

j. Meminimalisir kesenjangan (reduced inequalities): meminimalisir gap, baik di dalam sebuah negara maupun antar negara di dunia;

k. Keberlanjutan komunitas dan kota (sustainable communities and cities): mengkonstruksi pemukiman yang berkualitas, berkelanjutan dan aman;

1. Produksi dan konsumsi yang bertanggungjawab (responsible production and consumption): menjamin keberlangsungan pola produksi dan konsumsi;

m. Aksi terhadap iklim (climate action): merespon cepat guna memerangi perubahan iklim;

n. Kehidupan bawah laut (life below water): menjamin keberlangsungan laut dan kehidupan sumber dayanya guna pengembangan yang berkesinambungan;

o. Kehidupan di darat (life on land): meningkatkan dan mengembalikan kesinambungan ekosistem darat, mengelola hutan secara berkesinambungan, meminimalisir tanah tandus dan tukar guling tanah;

p. Peradilan dan perdamaian yang kuat (peace and justice strong institutions). Meningkatkan perdamaian termasuk masyarakat untuk pembangunan berkelanjutan, menyediakan akses berkeadilan bagi semua;

q. Kemitraan guna mencapai tujuan (partnership for the goals): Memperkuat implementasi serta menghidupkan kembali partnership global demi pembangunan yang berkesinambungan.

Agar sesuai dengan prinsip-prinsip Islam, maka The Global Goals harus ditelaah lebih dahulu dengan mengacu pada maqashid syariah kontemporer. 
Jurnal Iqtisad: Reconstruction of Justice and Welfare for Indonesia - Vol. 6, No 2 (2019) P-ISSN:

\section{SDGs dalam Perspektif Maqashid Syari’ah}

Belakangan ini, dunia mulai merasakan urgensinya poin-poin kesepakatan SDGs UNDP. Kebutuhan global itu bisa dirasakan di berbagai belahan dunia, misalnya perbaikan sanitasi untuk mencegah banjir, kebutuhan akan ketersediaan air bersih, aksi reboisasi, penanaman pohon dan penghijauan guna mencegah iklim agar tidak terjadi global warming, melestarikan berbagai hayati, menjaga terumbu karang di bawah laut serta lahan konservasi hewan langka yang dilindungi. Semua itu harus diupayakan oleh semua pihak. Maka harus terwujud keterjalinan antar berbagai unsur dalam mencapai tujuan yang telah disepakati.

Lalu bagaimanakah tujuan-tujuan hukum Islam (maqashid syari'ah) dalam memandang 17 point The Global Goals SDGs yang bertujuan memelihara kesinambungan pembangunan dunia dan kemanusiaan?

Berikut ini 17 poin The Global Goals dalam perspektif maqashid syariah:

\begin{tabular}{|c|c|c|c|c|}
\hline No. & $\begin{array}{c}\text { Klasifikasi } \\
\text { Maqashid } \\
\text { Klasik }\end{array}$ & SDGs & $\begin{array}{c}\text { Maqashid } \\
\text { Syari'ah Jasser } \\
\text { Auda }\end{array}$ & Fitur Sistem Maqashid \\
\hline 1. & Hifdz Din & $\begin{array}{l}\text { (16) Peradilan } \\
\text { yang Kuat dan } \\
\text { Perdamaian }\end{array}$ & $\begin{array}{l}\text { Maqashid } \\
\text { 'Ammah }\end{array}$ & $\begin{array}{l}\text { - } \text { Nature } \\
\text { Cognitive } \\
\text { - Purposefulness }\end{array}$ \\
\hline 2. & Hifdz Nafs & $\begin{array}{l}\text { (3) Kesejahteraan } \\
\text { dan Kesehatan } \\
\text { yang Baik } \\
\text { (11) } \\
\text { Keberlanjutan }\end{array}$ & $\begin{array}{l}\text { Maqashid } \\
\text { 'Ammah }\end{array}$ & $\begin{array}{l}\text { - Openness } \\
\text { - } \quad \text { Purposefulness }\end{array}$ \\
\hline
\end{tabular}


Jurnal Iqtisad: Reconstruction of Justice and Welfare for Indonesia - Vol. 6, No 2 (2019) P-ISSN:

\begin{tabular}{|c|c|c|c|c|}
\hline & & $\begin{array}{l}\text { Kota dan } \\
\text { Komunitas }\end{array}$ & $\begin{array}{l}\text { Maqashid } \\
\text { Khassah }\end{array}$ & $\begin{array}{l}\text { - } \text { Openness } \\
\text { - } \text { Multidimentiona } \\
\text { lity } \\
\text { - } \quad \text { Purposefulness }\end{array}$ \\
\hline 3. & Hifdz Irdh & $\begin{array}{l}\text { (5) Kesetaraan } \\
\text { Gender }\end{array}$ & $\begin{array}{l}\text { Maqashid } \\
\text { 'Ammah }\end{array}$ & $\begin{array}{l}\text { - Purposefulness } \\
\text { - Openness } \\
\text { - Wholeness }\end{array}$ \\
\hline 4. & Hifdz Aql & $\begin{array}{l}\text { (4) Pendidikan } \\
\text { Berkualitas }\end{array}$ & $\begin{array}{l}\text { Maqashid } \\
\text { 'Ammah }\end{array}$ & $\begin{array}{l}\text { - Multidimentionality } \\
\text { - Wholeness } \\
\text { - Purposefulness }\end{array}$ \\
\hline 5. & Hifdz Nasl & $\begin{array}{l}\text { (17) Kemitraan } \\
\text { guna Mencapai } \\
\text { Tujuan; } \\
\text { (6) Sanitasi dan } \\
\text { Air Bersih } \\
\text { (13) Aksi } \\
\text { terhadap Iklim } \\
\text { (14) Kehidupan } \\
\text { Bawah Laut } \\
\text { (15) Kehidupan } \\
\text { di Darat }\end{array}$ & $\begin{array}{l}\text { Maqashid } \\
\text { Khassah } \\
\text { Maqashid } \\
\text { 'Ammah } \\
\text { Maqashid } \\
\text { 'Ammah } \\
\text { Maqashid } \\
\text { 'Ammah } \\
\text { Maqashid } \\
\text { 'Ammah }\end{array}$ & $\begin{array}{l}\text { - } \text { Interrelated } \\
\text { - } \quad \text { Purposefulness } \\
\text { - } \text { Interrelated } \\
\text { - } \quad \text { Purposefulness } \\
\text { - Interrelated } \\
\text { - } \text { Purposefulness } \\
\text { - Interrelated } \\
\text { - } \text { Purposefulness } \\
\text { - Interrelated } \\
\text { - } \text { Purposefulness }\end{array}$ \\
\hline 6. & Hifdz Mal & $\begin{array}{l}\text { (1) Nir } \\
\text { Kemiskinan } \\
\text { (2) Nir Kelaparan } \\
\text { (7) Energi } \\
\text { Terjangkau dan } \\
\text { Bersih } \\
\text { (8) Pertumbuhan }\end{array}$ & $\begin{array}{l}\text { Maqashid } \\
\text { 'Ammah } \\
\text { Maqashid } \\
\text { 'Ammah } \\
\text { Maqashid }\end{array}$ & $\begin{array}{l}\text { - } \\
\text { - Interrelated } \\
\text { - } \quad \text { Wholeness } \\
\text { - Purposefulness }\end{array}$ \\
\hline
\end{tabular}


Jurnal Iqtisad: Reconstruction of Justice and Welfare for Indonesia - Vol. 6, No 2 (2019) P-ISSN:

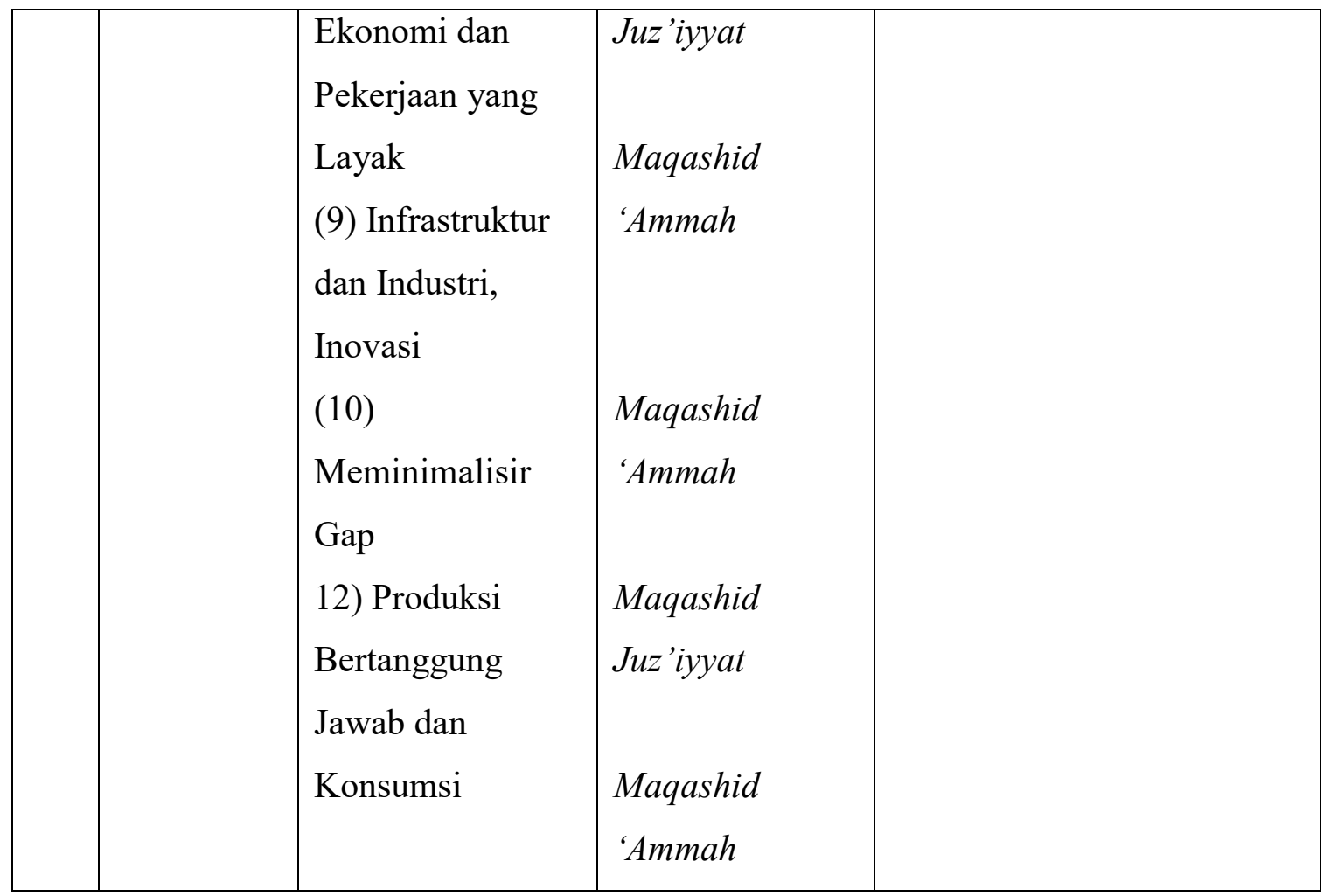

D. Simpulan

Reformulasi teori maqashid yang diupayakan Auda mengkritik maqashid klasik yang lebih pyramidal dan hirarkis. Penekanan maqashid klasik lebih pada preservation dan protection. Sedangkan maqashid baru lebih mengutamakan development dan rights. Auda menempatkan tawaran human development sebagai tekanan utama dari maslahah (public interest). Tawaran pendekatan sistem yang dilakukan Auda meliputi 6 fitur: interrelated; nature cognitive; multi dimentionality; wholeness; openness; dan purposefulness.

Pendekatan sistemik yang diinisiasi Jasser Auda merupakan pendekatan yang diadopsi dari beragam pendekatan. Hal demikian merupakan metoda baru dalam konteks sejarah pemikiran legislasi Islam.

Konsep Sustainable Development Goals yang terangkum dalam 17 poin The Global Goals dalam perspektif maqashid syariah Jasser Auda dapat 
Jurnal Iqtisad: Reconstruction of Justice and Welfare for Indonesia - Vol. 6, No 2 (2019) P-ISSN:

terklasifikasi berdasarkan maqashid 'ammah, khassah dan juz'iyyat yang di dalamnya dipilah berdasarkan 6 fitur maqashid syari'ah Jasser Auda, yaitu; interrelated; wholeness; openness; multi dimentionality, nature cognitive; dan purposefulness.

Setidaknya, menurut penulis, teori maqashid sistemik Jasser Auda terdapat beberapa catatan, antara lain:

1. Keunggulan yang ditawarkan maqashid versi Auda ialah ditawarkannya teori human development sebagai target maslahah.

2. Walaupun diklaim sebagai satu kesatuan holistik, namun pembedaan maqashid syari'ah yang terdiri dari maqashid 'ammah, juz'iyyat dan khassah amatlah mirip dengan kategorisasi maqashid klasik dharuriyat, hajjiyat dan tahsiniyat.

3. Maqashid syari'ah sistemik ini akan nampak kebermaknaannya jika dilihat dalam satu kesatuan yang utuh. Ini artinya jika ada salah satu ciri tersebut yang dihilangkan maka sesuatu tidak bisa disebut sebagai sistem lagi.

4. Dengan terlalu menekankan fitur kognitif, implikasinya adalah seolah pengetahuan hukum Islam hanya berada pada tataran pengetahuan (knowledge), padahal tujuan dari mempelajari ilmu adalah amal. Akibatnya, ranah afektif sebagai value system dan psikomotorik sebagai realisasi dari aktualisasi akhlaq akan terbengkalai.

5. Fitur kulliyat (wholeness) jika diakomodir akan mengebiri konsep dilalat an-nash dalam kajian Ushul Fiqh.

6. Salah satu dampak mendasar fitur interrelated hierarchy milik Jasser Auda ini ialah klasifikasi berdasarkan dharuriyyat, hajiyyat maupun tahsiniyyat akan diukur sama pentingnya.

7. Fitur multidimensional meniscayakan model ijtihad jama' $i$ (konsensus), hingga tanpa disadari menutup pintu ijtihad dengan 
Jurnal Iqtisad: Reconstruction of Justice and Welfare for Indonesia - Vol. 6, No 2 (2019) P-ISSN:

sendirinya, sebab pendekatan interdisipliner amatlah sulit ditemukan dalam diri seseorang.

8. Melalui fitur multidimensional, oposisi biner antara qath'i dan dzanni akan semakin kabur.

9. Bila terlalu menitikberatkan pada dilalatul maqashid, maka konsepkonsep ushul fiqh klasik seperti dzahir, nash, muhkam, mutasyabih, mujmal-mubayyan, mutlaq-muqayyad akan tersingkir dengan sendirinya.

10. Dengan menggunakan paradigma filsafat sistem, konsekuensinya konsep sebab dan syarat akan diminimalisir.

11. Melalui paradigma sistemik milik Jasser Auda, paradigma hukum Islam akan mengalami pergeseran, beralih dari bayani ke burhani. 
Jurnal Iqtisad: Reconstruction of Justice and Welfare for Indonesia - Vol. 6, No 2 (2019) P-ISSN: 2303-3223; E-ISSN: 2621-640X

\section{Daftar pustaka}

Abdullah, Amin, Pengantar dalam Membumikan Hukum Islam Melalui Maqashid Shari'ah, Bandung: PT Mizan Pustaka, 2015.

Al-Afriqi, Ibn Mansur, Lisan al- 'Arab (Beirut: Dar ash-Shadr, t.th), VIII.

Al-Ulwani, Taha Jabir, Muqaddimat al-Ma'had dalam Ahmad arRaisuni,Nazariyat al-Maqashid 'Inda al-Imam asy-Syatibi, Herndon:International Institute of Islamic Thought, 2007.

Ar-Raisuni, Ahmad, Nazariyat al-Maqashid 'Inda al-Imam asy-Syatibi, Herndon: International Institute of Islamic Thought, 2007.

Auda, Jasser, Maqasid al-Shariah as Philosophy of Islamic Law: A Systems Approach, (London: the International Institut of Islamic Thougth, 2007).

, Al-Maqashid untuk Pemula, Terj. Ali Abdelmo'im, (Yogyakarta: SUKA-Press, 2013).

, Membumikan Hukum Islam Melalui Maqashid Shari'ah, Bandung: PT Mizan Pustaka, 2015.

, Memahami Maqashid Syari'ah: Peranan Maqashid dalam Pembaharuan Islam Kontemporari, Selangor: PTS Islamika SDN, BHD, 2014.

, Maqashid al-Ahkam al-Shar'iyyah wa 'Ilaluha, diunduh

dari

http://www.jasserauda.net/modules/Research_Articles/pdf/article1A.p df diakses pada 13 Juli 2019.

, biografi, (online), Tersedia : http://www.jasserauda.net/ portal/biography/?lang=en), diakses 12 Juli 2019. 
Jurnal Iqtisad: Reconstruction of Justice and Welfare for Indonesia - Vol. 6, No 2 (2019) P-ISSN: 2303-3223; E-ISSN: 2621-640X

Kontekstualisasi Maqashid Shari'ah. ...

Gumanti, Retna, Maqashid Syari'ah Menurut Jasser Auda (Pendekatan Sistem dalam Hukum Islam), Jurnal al-Himayah, Vol. 2 No. 1 Maret 2018.

Mutholingah, dkk., Siti, Relevansi Pemikiran Maqashid Al-Syari'ah Jasser Auda Terhadap Sistem Pendidikan Islam Multidisipliner, Jurnal Ta'limuna, Vol. 7 No. 2, September 2018.

Prihantono, Syukur, Maqashid Syari'ah dalam Pandangan Jasser Auda (Sebuah Upaya Rekonstruksi Hukum Islam dengan Pendekatan Sistem, Jurnal at-Tafkir, Vol. X No. 1 (Juni 2017).

Rahardjo, Ishartono dan Santoso Tri, Sustainable Development Goals (SDGS) dan Pengentasan Kemiskinan, Share: Social Work Journal, Vol. 6., No. 2, 2016, Fisip Universitas Padjajaran.

Wahyuningsih, Millenium Development Goals (MDGS) dan Sustainable Development Goals (SDGS) dalam Kesejahteraan Sosial, Bisma; Jurnal Bisnis dan Manajemen, Vol. 11, No. 3, September 2017.

www.globalgoals.org dan satu-indonesia.com, diakses pada 14 Juli 2019. 